\title{
TGIF1 Gene Silencing in Tendon-Derived Stem Cells Improves the Tendon-to-Bone Insertion Site Regeneration
}

\author{
Liyang Chen ${ }^{a, b} \quad$ Chaoyin Jiang ${ }^{c}$ Shashi Ranjan Tiwari ${ }^{b}$ Amrit Shrestha ${ }^{b}$ \\ Pengcheng $\mathrm{Xu}^{\mathrm{b}}$ Wenqing Liang ${ }^{\mathrm{d}}$ Yeqing Sun ${ }^{\mathrm{b}}$ Shisheng $\mathrm{He}^{\mathrm{a}, \mathrm{b}}$ Biao Cheng ${ }^{\mathrm{b}}$ \\ aShanghai Clinical College, Anhui Medical University, Hefei, 'bepartment of Orthopedics, Shanghai \\ Tenth People's Hospital, Tongji University, School of Medicine, Shanghai, 'Department of Orthopedics, \\ Shanghai Jiao Tong University Affiliated Sixth People's Hospital, Shanghai, dDepartment of \\ Orthopaedics, Shaoxing People's Hospital, Shaoxing, China
}

\section{Key Words}

Tendon-derived stem cells • TGF- $\beta$-TGIF1 • Tendon-to-bone $\bullet$ Regeneration

\begin{abstract}
Background/Aims: The slow healing process of tendon-to-bone junctions can be accelerated via implanted tendon-derived stem cells (TDSCs) with silenced transforming growth interacting factor 1 (TGIF1) gene. Tendon-to-bone insertion site is the special form of connective tissues derivatives of common connective progenitors, where TGF- $\beta$ plays bidirectional effects (chondrogenic or fibrogenic) through different signaling pathways at different stages. $A$ recent study revealed that TGF- $\beta$ directly induces the chondrogenic gene Sox9. However, TGIF1 represses the expression of the cartilage master Sox9 gene and changes its expression rate against the fibrogenesis gene Scleraxis (Scx). Methods: TGIF1 siRNA was transduced or TGIF1 was over-expressed in tendon-derived stem cells. Following suprapinatus tendon repair, rats were either treated with transduced TDSCs or nontransduced TDSCs. Histologic examination and Western blot were performed in both groups. Results: In this study, the silencing of TGIF1 significantly upregulated the chondrogenic genes and markers. Similarly, TGIF1 inhibited TDSC differentiation into cartilage via interactions with TGF- $\beta$-activated Smad 2 and suppressed the phosphorylation of Smad2. The area of fibrocartilage at the tendon-bone interface was significantly increased in the TGIF1 (-) group compared with the control and TGIF1-overexpressing groups in the early stages of the animal model. The interface between the tendon and bone showed a increase of new bone and fibrocartilage in the TGIF1 (-) group at 4 weeks. Fibrovascular scar tissue was observed in the TGIF1-overexpressing group and the fibrin glue only group. Low levels of fibrocartilage and fibrovascular scar tissue were found in the TDSCs group. Conclusion: Collectively, this study shows that the tendon-derived stem cell modified with TGIF1 gene silencing has promising effects on tendon-to-bone healing which can be further explored as a therapeutic tool in regenerative medicine.

Copyright $(2015$ S. Karger AG, Basel

L. Chen and C. Jiang contributed equally to this work and should be considered co-first authors.

Biao Cheng and Shisheng He

Shanghai Clinical College, Anhui Medical University, Hefei 230032, (China); and Department of Orthopedics, Shanghai Tenth People's Hospital, Tongji University, School of Medicine, Shanghai 200072, (China)

E-Mail cbiao6@yeah.net and heshisheng123@126.com
\end{abstract}

KARGER 125 


\section{Introduction}

The tendon-bone injury is one of the critical medical challenges among active young individuals, athletes or the elderly due to long recovery process and poor healing outcome. The factors include the relative avascularity of the fibrocartiliage zone, bone loss at the site of injury $[1,2]$. Tendon disorders are commonly due to injuries, diseases, age-related factors or anatomical abnormalities. All the associated cause factors of tendon disorders contribute to the poor tendon healing process or failure of healing [3]. The recent reports showed that the tendon disorders are mostly induced by degenerations or tendon wear [4, 5]. In spite of the poor outcome, the conservative strategies to treat tendon injury include RICE (rest, ice, compression, elevation), immobilization, splinting, pain and swelling management of injury sites and re-injuries or surgical interventions. All these conservative treatments focus on the self-healing of the affected tendons. However, the enthesis injury within the fibrocartilaginous region leads to tendon stiffness and poor prognosis at the insertion site. The articulate surface of the tendon insertion is composed of fibrocartilage and mineralized fibrocartilage [6,7]. Lack of blood supply causes limited repair capabilities and slow deposition of new matrix. Furthermore, terminally plotted chondrocytes are bounded and cannot proliferate or migrate to the areas of bone loss or damages.

Mineralization is a progressive phenomenon in adults at the junction between tendon and bone, where articular calcified cartilages are formed. Fibrocartilage and mineralized fibrocartilage that contains cartilage and type II collagen are unique types of connective tissues originated from the common connective progenitor tissues [7]. TGF- $\beta$ is considered to be the major regulators in the differentiation and growth of the skeletal connective tissues such as tendon, cartilage and bone $[7,8]$. TGF- $\beta$ has been shown to regulate chondrocytes growth and differentiation and have been used to improve the generations of cartilage and tissues in vitro [9].

During the differentiation process, interactions between TGF- $\beta$ and TGIF1 modulate the chondrogeneic and fibrogenic pathways by repressing chondrogenic gene (Sox9, Aggrecan and Collagen type II) and by upregulating tendon markers (Scleraxis, Tenomodulin and Collagen type I) [8]. TGIF1 belongs to the three-amino-acid loop extension (TALE) subfamily of homeodomain proteins $[8,10,11]$. TGIF functions as a transcriptional co-repressor that directly associates with Smad proteins and inhibits Smad-mediated transcriptional activation $[12,13]$. TGIF1 is constitutively localized in the nucleus. The interaction of TGIF1 with Smads leads to the recruitment of TGIF1 into the Smad-responsive elements, thereby repressing TGF- $\beta$-activated genes.

Our previous study demonstrated that TDSCs are able to differentiate into chondrocytes, osteocytes, and adipocytes [14]. Based on our previous results [14-16], we hypothesized that the tendon-derived stem cells modified with TGIF1 gene silencing will improve the regeneration of the tendon-to-bone insertion site. This study aimed to explore the possibilities of upregulated regenerative or re-healing tendons at the tendon-to-bone insertion site via transplanting TDSCs modified with TGIF1 gene silencing.

\section{Materials and Methods}

\section{Animals and Study Groups}

From seventy-four Sprague-Dawley rats (7 - 8 weeks old) [17] supplied by Shanghai Super, B\&K Laboratory Animal Corp. Ltd. were used in this study. Ten rats were used for TDSC harvest. A total of sixtyfour Sprague-Dawley rats (7-8 weeks) were randomized into experimental groups (32 rats) and control groups (32 rats). Both experimental groups were divided into experimental group A: TDSC + TGIF1 (-) standing for TGIF1 silencing group, and experimental group B: TDSC + TGIF1 (+), standing for TGIF1 overexpressing group. The control groups are group A: TDSC (without TGIF1) and group B: contains fibrin glue only (without TDSC and TGIF1). The Animal Research Ethics Committee at Shanghai Tenth People's Hospital approved all the experiments. 


\section{Cellular Physiology Cell Physiol Biochem 2015;37:2101-2114 \begin{tabular}{ll|l} 
and Biochemistry Published online: November 25, 2015 & $\begin{array}{l}\text { (c) 2015 S. Karger AG, Basel } \\
\text { www.karger.com/cpb }\end{array}$ \\
\hline
\end{tabular} \\ Chen et al.: TDSCs Silencing TGIF1 Promote Tendon-to-Bone Healing}

Isolation and culture of rat TDSCS

For TDSC isolation [18-20], the mid-substance of Achilles tendons was excised from healthy rats overdosed with $2.5 \%$ intraperitoneal sodium phenobarbital $(1.0 \mathrm{~mL} / 400 \mathrm{~g})$. Peritendinous connective tissue was carefully removed, and the tissue was stored in sterile phosphate buffered saline (PBS). The tissues were minced, digested with type I collagenase (3 mg/mL; Sigma-Aldrich) and passed through a 70-mm cell strainer (Becton Dickinson, Franklin Lakes, NJ) to yield a single-cell suspension. The isolated cells were washed in PBS and resuspended in low-glucose Dulbecco's modified Eagle medium (Gibco BRL; Life Technologies, Invitrogen, Carlsbad, CA), with 10\% fetal bovine serum, $50 \mathrm{mg} / \mathrm{mL}$ penicillin, $50 \mathrm{mg} / \mathrm{mL}$ streptomycin, and $100 \mathrm{mg} / \mathrm{mL}$ neomycin (complete culture medium) (Invitrogen Corporation, Carlsbad, CA). The isolated nucleated cells were plated at the optimal low plating cell density $\left(500 \mathrm{cells} / \mathrm{cm}^{2}\right)$ for the isolation of stem cells and cultured at $37^{\circ} \mathrm{C}, 5 \%$ carbon dioxide $\left(\mathrm{CO}_{2}\right)$ to form colonies. At day 2 after initial plating, the cells were washed twice with phosphate buffered saline (PBS) to remove the non-adherent cells. On days 7 to 10 , they were trypsinized and mixed together as passage 0 (P0).

\section{Chondrogenic differentiation assay}

For chondrogeneic differentiation, a pellet culture system (density, $8 \times 10^{5}$ cells $/ \mathrm{ml}$ ) [19] was used to compare the chondrogenic differentiation of TDSCs transfected with TGIF1 siRNA and over-expression of TGIF1. TDSCs were cultured in chondrogenic medium contained LG-DMEM (HyClone, Pittsburgh, USA), supplemented with $10 \mathrm{ng} / \mathrm{mL}$ transforming growth factor beta (R\&D Systems, Inc., Minneapolis, USA), $100 \mathrm{nM}$ dexamethasone, $50 \mu \mathrm{g} / \mathrm{mL}$ of ascorbic acid-2-phosphate, $100 \mu \mathrm{g} / \mathrm{mL}$ sodium pyruvate, $40 \mu \mathrm{g} / \mathrm{mL}$ proline (all from Sigma-Aldrich, St. Louis, USA), 1\% insulin, transferrin, and sodium selenite (ITS) (Gibco, Grand Island, USA) +mix, and 1\% penicillin-streptomycin(Gibco, Grand Island, USA)). At day 21, the cell pellets were stained with toluidine blue for proteoglycans (PGs) detection $[9,18]$.

\section{Quantitative real-time polymerase chain reaction}

Total RNA was isolated from cultured cells and frozen tissue samples using Trizol (Invitrogen, USA) following the manufacturer's instructions. Reverse transcription was carried out with $2 \mu \mathrm{g}$ of total RNA from each sample using SuperScript II RT kit (Invitrogen, Carlsbad, CA). Quantitative real-time PCR was conducted using SYBR Green PCR master mix (Applied Biosystems) on an ABI 7500HT System (Applied Biosystems, Foster city, CA). Primer sequences and conditions for qualitative real-time polymerase chain reaction are shown in Table 1 . The relative expression levels of each gene were calculated and normalized using the $2^{-\Delta \Delta \mathrm{Ct}}$ method relative to detected $\beta$-actin levels. All reactions were repeated in triplicate.

Table 1. Primer Sequences and Conditions for Qualitative Real-Time Polymerase Chain Reaction

\begin{tabular}{|c|c|c|c|c|}
\hline Gene & Primer nucleotide sequence & $\begin{array}{l}\text { Product } \\
\text { size(bp) }\end{array}$ & $\begin{array}{c}\text { Annealing } \\
\text { temperature, }{ }^{\circ} \mathrm{C}\end{array}$ & $\begin{array}{c}\text { Accession } \\
\text { number }\end{array}$ \\
\hline Sox9 & $\begin{array}{l}\text { 5'- AGAGCGTTGCTCGGAACTGT -3' } \\
\text { (Forward) } \\
\text { 5'-TCCTGGACCGAAACTGGTAAA- } \\
\text { 3'(Reverse) }\end{array}$ & 67 & 60 & XM_343981.2 \\
\hline Aggrecan & $\begin{array}{l}\text { 5'-CTTGGGCAGAAGAAAGATCG - } \\
3^{\prime} \text { (Forward) } \\
5^{\prime} \text {-GTGCTTGTAGGTGTTGGGGT - } \\
3^{\prime} \text { (Reverse) }\end{array}$ & 159 & 58 & NM_022190.1 \\
\hline Collagen type 2 a1 & $\begin{array}{l}5^{\prime} \text { - CCGGACTGTGAGGTTAGGAT -3' } \\
\text { (Forward) } \\
5^{\prime} \text { - AACCCAAAGGACCCAAATAC -3' } \\
\text { (Reverse) }\end{array}$ & 101 & 58 & NM_012929.1 \\
\hline Scleraxis(Scx) & $\begin{array}{l}\text { 5'-AACACGGCCTTCACTGCGCTG-3' } \\
\text { (Forward) } \\
\text { 5'-CAGTAGCACGTTGCCCAGGTG-3' } \\
\text { (Reverse) }\end{array}$ & 102 & 58 & NM_001130508.1 \\
\hline Tenomodulin(Tnmd) & $\begin{array}{l}\text { 5'-GTGGTCCCACAAGTGAAGGT-3' } \\
\text { (Forward) } \\
5^{\prime} \text {-GTCTTCCTCGCTTGCTTGTC-3' } \\
\text { (Reverse) }\end{array}$ & 60 & 52 & NM_022290.1 \\
\hline Collagen type $1 \mathrm{a} 1$ & $\begin{array}{l}5^{\prime} \text {-CATCGGTGGTACTAAC-3' (Forward) } \\
5^{\prime} \text {-CTGGATCATATTGCACA-3'(Reverse) }\end{array}$ & 238 & 50 & NM_053356.1 \\
\hline$\beta$-actin & $\begin{array}{l}5^{\prime} \text {-ATCGTGGGCCGCCCTAGGCA-3' } \\
\text { (Forward) } \\
5^{\prime} \text {-TGGCCTTAGGGTTCAGAGGGG-3' } \\
\text { (Reverse) }\end{array}$ & 243 & 52 & NM_031144.2 \\
\hline
\end{tabular}




\section{Cellular Physiology Cell Physiol Biochem 2015;37:2101-2114 \begin{tabular}{ll|l} 
and Biochemistry $10.1159 / 000438568$ & Published online: November 25, 2015 & $\begin{array}{l}\text { C 2015 S. Karger AG, Basel } \\
\text { www.karger.com/cpb }\end{array}$ \\
\hline
\end{tabular} \\ Chen et al.: TDSCs Silencing TGIF1 Promote Tendon-to-Bone Healing}

\section{Expression vectors}

Gene expression associated with chondrogenesis (Sox9, Aggrecan and Collagen II) or tenogenesis (Scleraxis, Tenomodulin and Collagen I)) were studied at different timepoints in control and experimental culture groups. At days 3, 7, and 21, micromass cultures, qRT-PCR and Western blot were used to detect the gene expression involved in chondrgenesis. Protein extracts from insertion site 2 and 4 weeks during the insertion site healing were subjected to Western blotting to detect the protein levels of chondrogenic markers and tendon markers. TGIF constructs were created within a modified pCMV5 containing two copies of a HA epitope, pCMV5 HA TGIF1 (Addgene, Cambridge, MA, USA) [21, 22]. A flag-tagged Smad2 construct was in pCS2 (Addgene, Cambridge, MA, USA). Expression vectors for HA-TbRI or HA-TbRI.act were described as previously $[23,24]$.

\section{Gene Silencing using siRNA}

The TGIF1 function was reduced by small interference siRNA treatment. For the optimal knockdown and reduced off-targets: Rat TGIF1 siRNA (L-085413-02, Dharmacon, Lafayette, LA, USA) or non-targeting negative control siRNA (GE Dharmacon, Lafayette, LA, USA); Rat Smad2 siRNA (L-091698-02, GE Dharmacon, Lafayette, LA, USA) and non-targeting negative control siRNA (Dharmacon, Lafayette, LA, USA) were used. TGIF1siRNA sequences (highlighted sequence was the complementary sequence with TGIF1 mRNA) were listed as following: 5'- GGTGTTGTTGCAGCAGCATTT $-3^{\prime}$. Tendon-derived stem cells were transfected with TGIF1 siRNA or with scrambled siRNA. Twenty-four hours after transfection, cells were treated with TGF- $\beta$ for $1 \mathrm{hr}$. The expression of TGIF1 and the phosphorylation of Smad2 were assessed by immune blotting with anti-TGIF1 and anti-pSmad2.

\section{Immunoprecipitation}

In immunoprecipitaion, TDSC lysates were incubated overnight at $4^{\circ} \mathrm{C}$ with $1 \mu \mathrm{g}$ of anti-TGIF, followed by precipitation with $20 \mu \mathrm{l}$ of protein anti-HA (1/1000) [8], Immunoprecipitaes were boilded for 5 min in SDS sample buffer and were separated on SDS-poly acrylamine and blotted with anti-Smad antibody [8].

\section{Western Blotting}

Total proteins were extracted, separated by $12 \%$ sodium dodecyl sulphate-polyacrylamine gel electrophoresis (SDS-PAGE), and then transferred onto polyvinylidene fluride (PVDF) membranes (Millipore, MA, USA). Twenty micrograms of total RNA was loaded into each well stained with ethidium bromide in equal amount. The primary antibody used in this study included Anti-Smad2 (1/1000), antiphospho-Smad2 (1/1000), Anti-Sox9 (1/1000), Anti-Aggrecan (1/100), Anti-Collagen II (1/5000), Anti-Scx (1/250), Anti-Tenomodulin (1/300), Anti-Collagen I (1/5000) and Anti-beta Actin (1/1000) were purchased from Abcam (Cambridge, MA, USA). Monoclonal anti-Flag M2 were purchased from Sigma. Anti-TGIF was purchased from Santa Cruz Biotechnology (Dallas, TX, USA). Secondary Antibodies include goat polyclonal to rabbit IgG - H\&L-Pre-Adsorbed (HRP) at 1/2000 dilution. $\beta$-actin was served as loading control and was determined using a specific antibody.

\section{Animal Surger}

The following surgical procedure was performed on the 64 rats that were designated to undergo surgical detachment and repair of the supraspinatus tendon, was performed as previously described [14, $15,25]$.

The right shoulder was operated under general anesthesia to detach half of the supraspinatus tendon width from its insertion site on the humerus in all the four groups. A \#15 blade knife was used to clear the fibrocartilage completely from the greater tuberosity leaving a bleeding bone. A stitch was placed into the supraspinatus tendon. A 22-gauge needle was used to create two bone tunnels at the anterior and posterior margins of the insertion site. The sutures in the tendon were then passed through the tunnels. TDSCs were trypsinized after confluence and washed with PBS. The fibrin sealant (Tisseel, Baxter AG, Vienna, Austria) was composed of 2 separate solutions. Solution A contains thrombin dissolved in $40 \mathrm{nmol} / \mathrm{L}$ calcium chloride. Solution B was prepared through dissolving Tisseel in $3000 \mathrm{KIU} / \mathrm{mL}$ aprotinin. $10^{6}$ TDSCs were mixed with $25 \mathrm{ml}$ of Solution A. The cell suspension was mixed with $25 \mathrm{ml}$ of fibrin glue solution B. The fibrin glue ((Tisseel, Baxter AG, Vienna, Austria)) constructs with TDSCs $\left(10^{6}\right.$ cells) were placed in the tendon defect horizontally with the length and width of the construct fitted into the size at the wound in all groups 
according to the mentioned criteria. During preliminary trials of the surgical procedure, it was determined that $50 \mathrm{ml}$ of fibrin sealant should be applied to the supraspinatus footprint due to its small size. At weeks 2 and 4 post surgery, eight animals in each group were sacrificed and the supraspinatus tendon from the insertion site was harvested. The insertion site was processed for western blotting and histolodical analysis.

\section{Histological Analysis}

Five rats in each group were sacrificed at 2 and 4 weeks for histologic examination, respectively. The tissue sections were stained with hematoxylin and eosin and safranin $0 /$ fast green. The stained sections with safranin 0 /fast green were analyzed to determine the total area of new fibrocartilage formation at the insertion site of the rotator cuff repair.

\section{Statistics analysis}

Data shown are representative of at least 3 independent experiments. The results are expressed as mean \pm SEM. The significance of differences was analysized by ANOVA followed by Student Newmann-Keuls multiple comparison tests and non-parametric tests. All statistical analyses were conducted using SPSS software (version 17.0, SPSS Inc., Chicago, IL). Statistical differences were considered significant at the $\mathrm{P}<$ 0.05 levels.

\section{Results}

The silencing of TGIF1 gene up regulates the chondrogenic markers and downregulates the tendon markers

TGIF1 silencing effect on TDSCs was assessed on day 3, 7 and 21 from micro-mass culture. Quantitative real-time polymerase chain reaction (PCR) and Western blott were used to detect the level of TGIF1 levels in transduced and nontransduced TDSCs (Fig. 1A, B). Chondrogenic markers (Sox9, Aggrecan and Collagen type II) were significantly upregulated in TGIF1 silenced group and the opposite phenomenon occurred in the TGIF1 overexpressing group (Fig. 2D). The difference between 7 and 21 days micro-mass cultures were statistically significant $(p<0.05)$, respectively. At 21 days micro-mass cultures, the expression of Sox9, Aggrecan and Col II were significantly upregulated in the TGIF1 silenced group compared to the control group, with $p<0.001, p=0.001, p<0.001$, respectively. In the TGIF1 overexpressing group, the expression of Sox9, Aggrecan and Col II were significantly down regulated, with $\mathrm{p}<0.001, \mathrm{p}=0.003, \mathrm{p}=0.001$, respectively. Western blot analysis of Sox9, Aggrecan and Col II confirmed the same findings (Fig. 2E). TGIF1 silencing group showed more specific toluidine blue staining of cartilage extracellular matrix than in TGIF1 overexpressing group and control group (Fig. 2A, B and C).

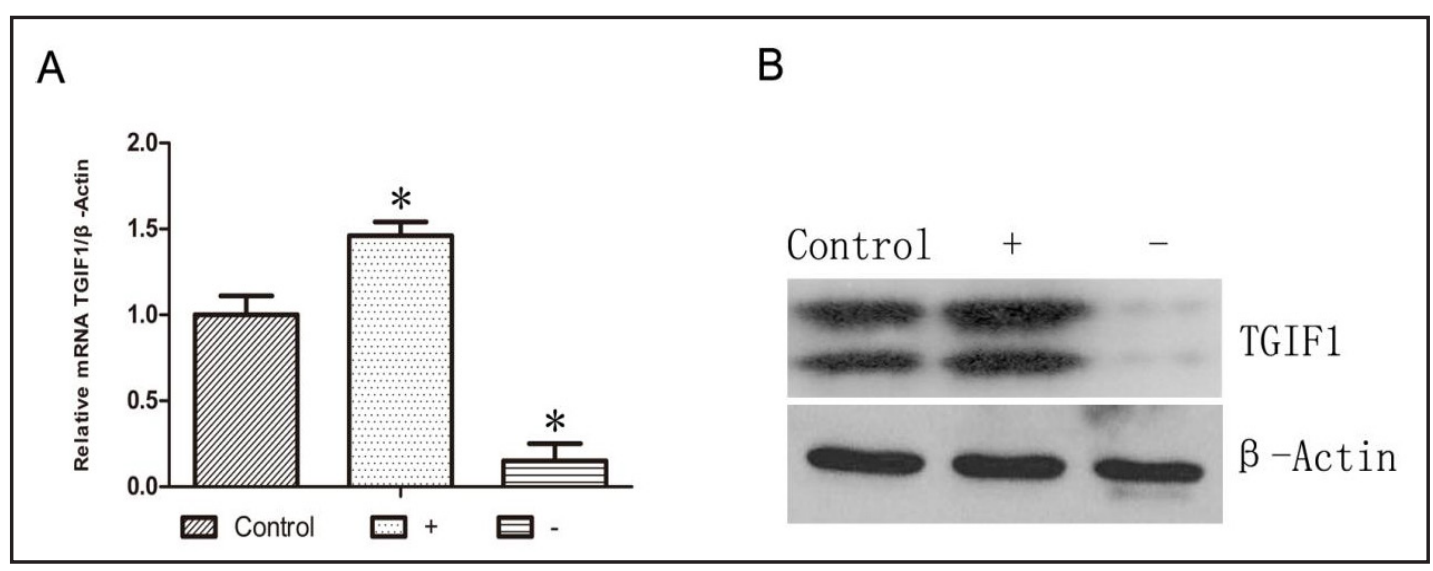

Fig. 1. Quantitative real-time polymerase chain reaction (PCR) and Western blotting demonstrate TGIF1 levels in transduced and nontransduced TDSCs. (-) TGIF1 silencing group; (+) TGIF1 overexpressing group. 


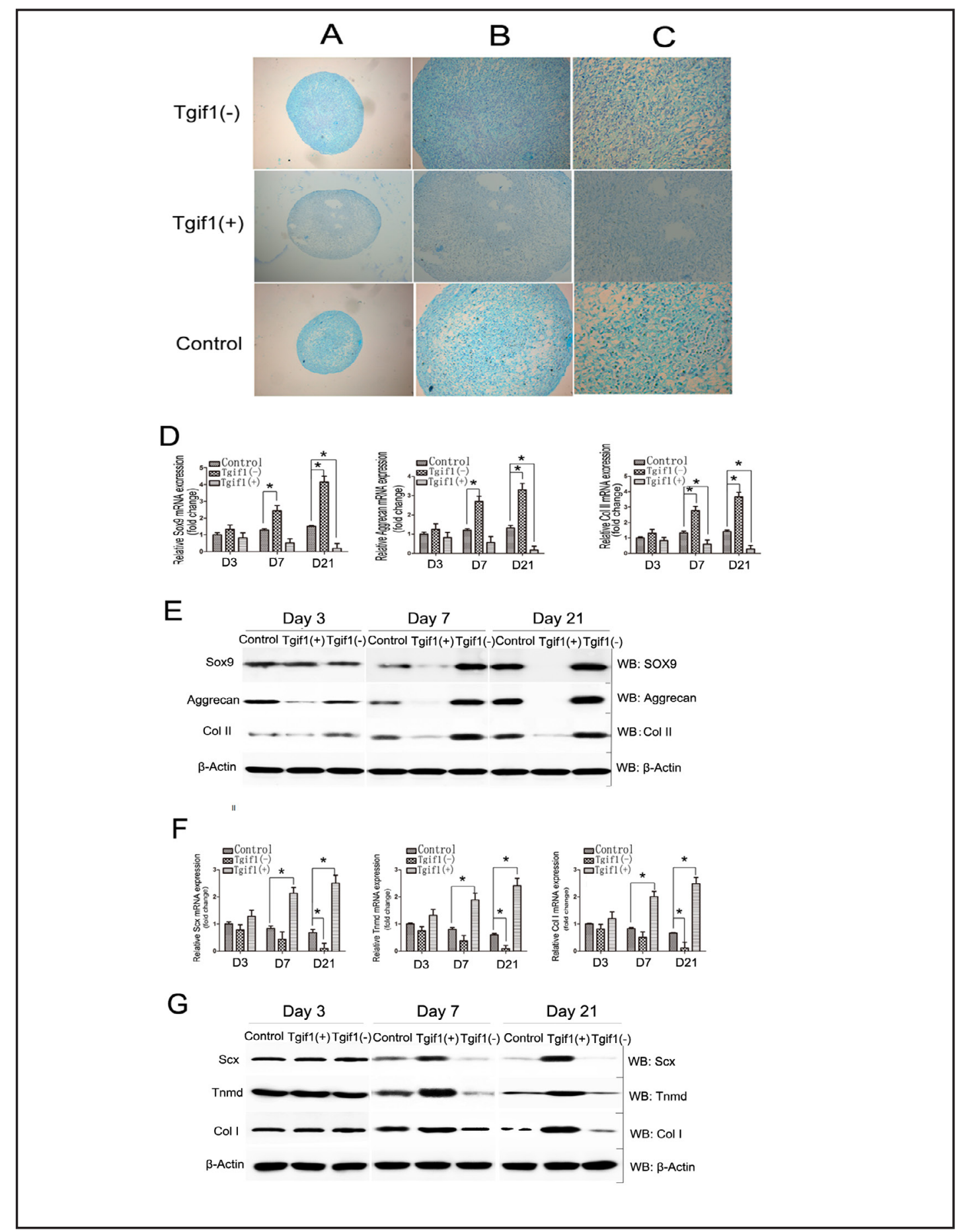

Fig. 2. (A, B and C) Twenty-one days micromass cultures treated with TGIF1 (-) / (+) and cultures representative of control at day 21 . The cell pellets stained with toluidine blue after sectioning of the pellets at $8 \mu \mathrm{m}$. (D) qPCR analysis of chondrogenic markers ( Sox9, Aggrecan and Col II) at 3, 7 and 21 days micromass cultures of tendon-derived stem cells treated with TGIF1 $(-) /(+)$ and cultures representative of control. (E) Expression analysis of Sox9, Aggrecan, Col II by Western blotting. (F) qPCR analysis of the expression of Scx, Tnmd and Col II at 3, 7 and 21 days micromass cultures of tendon-derived stem cells transfected with TGIF1 siRNA or TGIF1 overexpressing. (G) Expression analysis of Scx, Tnmd and Col I by Western blotting. Twenty micrograms of total RNA was loaded into each lane and equal loading was verified by staining with ethidium bromide. TGIF1 (-), SilencingTGIF1 gene; TGIF1 (+), over-expressing TGIF1 gene; * $\mathrm{p}<0.05$. 


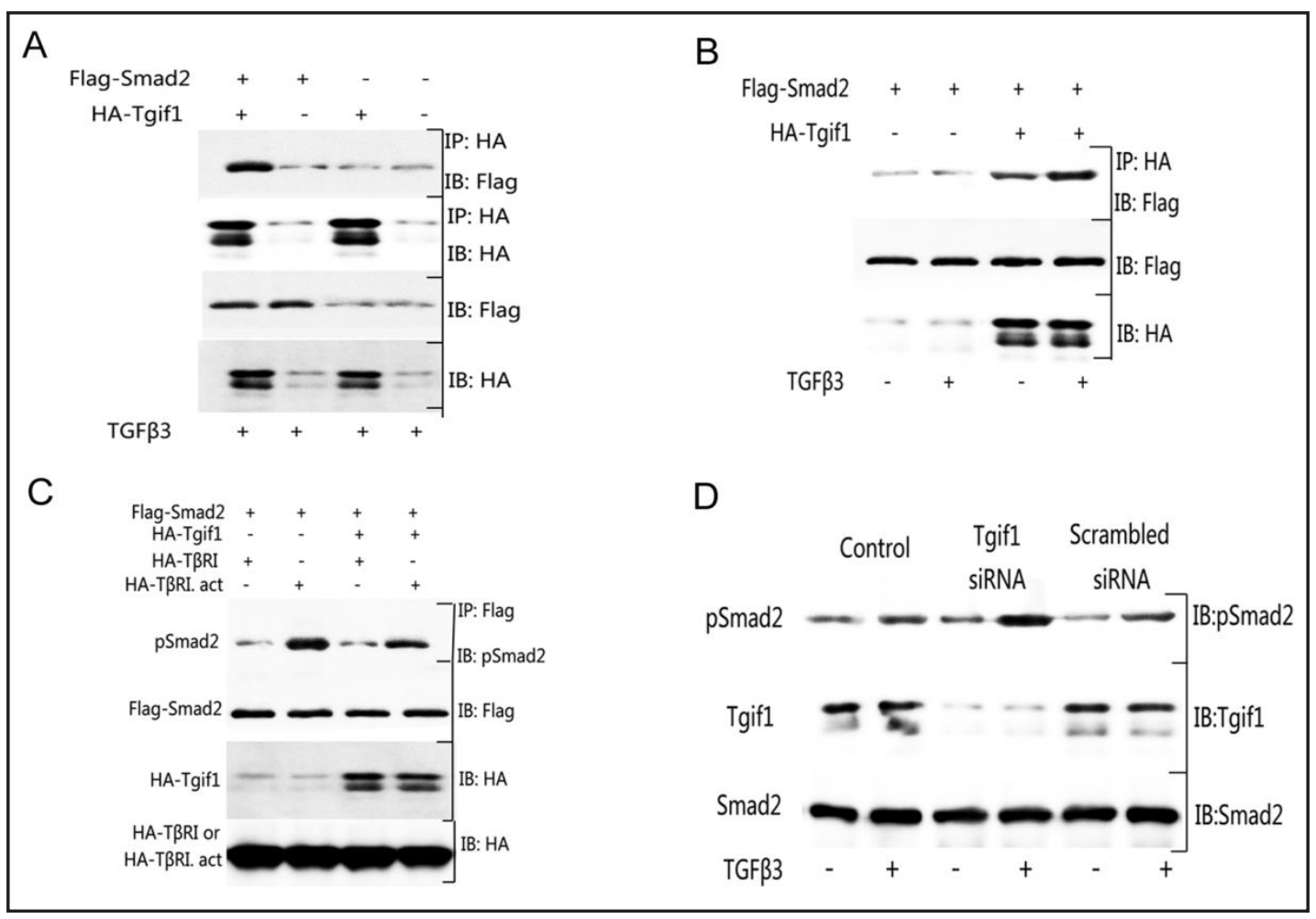

Fig. 3. TGIF1 repressed TGF- $\beta$-induced gene expression independently of its association with smad 2 and suppresses smad2 phosphorylation. (A and B) Tendon-derived stem cells transfected with the indicated combinations of Flag-Smad 2 and HA-TGIF1 was treated with or without TGF- $\beta$. Cell lysates were immunoprecipitated (IP) with anti-HA and immunoblotted (IB) with anti-Flag. (C) Tendon-derived stem cells were transfected with Flag-Smad2, HA-TGIF1, HA-T $\beta R I$, and HA-TßRI as indicated, and Smad2 phosphorylation was assessed by blotting the anti-Flag immunoprecipitated with anti-phospho-Smad2 (anti-pSmad2). (D) Tendon-derived stem cells were transfected with either TGIF1 siRNA or scrambled siRNA, and, $24 \mathrm{hr}$ after transfection. The samples were treated with TGF- $\beta$ for $1 \mathrm{hr}$. The expression of TGIF1 and the phosphorylation of Smad2 were assessed by immunoblotting with anti-TGIF1 and anti-pSmad2.

Overexpressed TGIF1 gene upregulates the expression of tendon markers and down regulates the chondrogenic markers

The expressions of tendon markers were significantly elevated in TGIF1 gene overexpressing group and chondrogeneic markers were remarkably reduced. Overexpressed TGIF1 gene promoted the differentiation of tenocytes and demoted chondrocytes. The quantitative real time PCR (qPCR) revealed that on day 3, 7, and 21, the expression of Scx, Tnmd and Col I were increased (Fig. 2F). Micromass cultures of tendon-derived stems cells transfected with TGIF1 siRNA or TGIF1 overexpressed were significantly different with $p<0.05$. At 21 days micro-mass cultures, the expression of Scx, Tnmd and Col I were significantly upregulated in the TGIF1 overexpressing group compared to the control group $(p<0.001$, respectively). In the TGIF1 silenced group, the expression of Scx, Tnmd and Col I were significantly downregulated $(\mathrm{p}<0.001$, respectively). Western blot also showed evident fibrogenesis markers (Scx, Tnmd and Col I) (Fig. 2G).

TGIF1 inhibits TDSC differentiation into cartilage through interaction with TGF $\beta$-activated Smad2 and suppresses phosphorylation of Smad2

To investigate the function of TGIF1, we expressed HA-Tgif1 with Flag-Smad2 in TDSCs. As shown in Fig. 3A, we observed that Tgif1 can bind the Smad2. Furthermore, the association 




Fig. 4. (A) Representative hematoxylin and eosin-stained tissue sections (100 × magnification) of the tendon insertion site at week 2 and 4 postoperatively. (B) Representative histology images of the fibrocartilage at the insertion site (100 ×magnification) as determined by metachromasia with safranin 0/fast greenstained slides. There was a greater area of metachromasia found in the TGIF1 (-) TDSC group. I interface; T tendon; B bone. TGIF1(-) silencing TGIF1 TDSCs group; TGIF1(+) overexpressing TGIF1 TDSCs group; Control 1, TDSCs group; control 2, fibrin glue group.

of Smad2 with TGIF1 was strongly increased in the existence of TGF $\beta$ (Fig. 3B). Interestingly, phosphorylation of Smad2 was decreased when more TGIF1 interacts with Smad2 (Fig. 3C), suggesting that Tgif1 can suppress the phosphorylation of Smad2.

Silencing TGIF1 increases the area of fibrocartilage at the tendon-bone interface in the early stage

The goal of histologic analysis was to identify the amount of chondroid tissue in each of the samples. The postoperative hematoxylin and eosin-stained tissue sections at the tendon insertion site at 2 and 4 weeks showed increasing area of fibrocartilage in the TGIF1 silencing group compared with the control and TGIF1 overexpressing group in the early stage (Fig. 4A). In the control groups and the TGIF1 over-expressing group, the level of fibrovascular granulation tissue was between the tendon and bone, but was not obvious in the TGIF1 silencing group.The formation of fibrovascular scar tissue was attenuated at 2 weeks after surgery in silencing group. However, inflammatory cells that primarily consisted of polymorphonuclear leukocytes and scar tissue were dominant in the TGIF1 


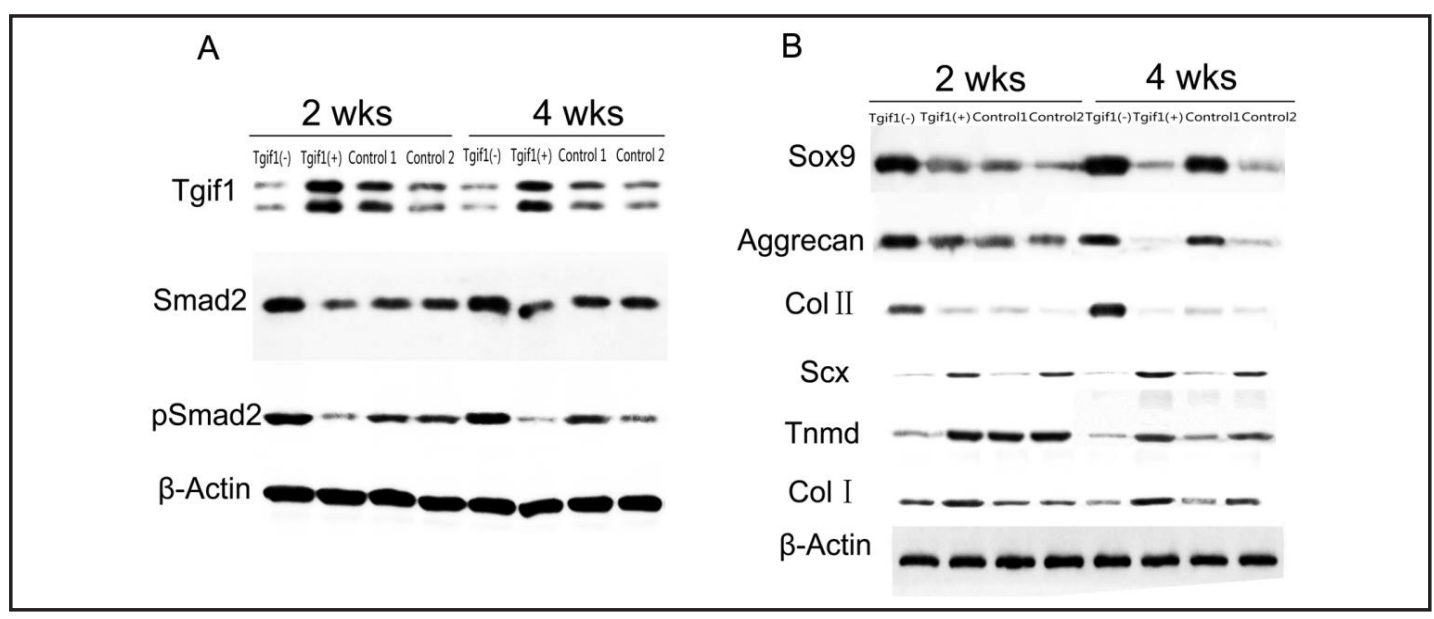

Fig. 5. The activation of TGF $\beta / \operatorname{Smad} 2$ signaling pathway and the protein levels of Chondrogenic/tenocyte markers during the insertion site healing. (A) The TGF $\beta / S m a d 2$ signaling activity in insertion site 2 and 4 weeks after the injection of treatment cocktails of silencing TGIF1 TDSCs, overexpressing TGIF1 TDSCs, TDSCs (control 1) or only fibrin glue (control 2) analyzed by western blotting of TGIF1, Smad2 and phosphorSmad2. (B) Protein levels of Chondrogenic markers (Sox9, Aggrecan and Collagen II) and tendon markers (Scx, Tnmd and Collagen I) depicted by western blotting of protein extracts from insertion site 2 and 4 weeks after the injection of treatment cocktails of silencing TGIF1 TDSCs, TGIF1 overexpressing TDSCs, TDSCs (control 1) or only fibrin glue (control 2). Beta-actin was used as a control for total protein quantity.

overexpressing group and the fibrin glue only group. Low levels of fibrovascular scar tissue were found in the TDSCs group. At 4 weeks, fewer inflammatory cells were found in the TGIF1 overexpressing group and the fibrin glue only group. However, there was no fibrocartilage formation in the tendon-bone insertion. Collagen organization was more disordered in the TGIF1 overexpressing group compared with the control groups. Bone ingrowth into the interface between the tendon and bone was very prominent TGIF1 silencing group at the 4 weeks.

Similarly, safranin 0 /fast green staining showed a greater area of metachromasia in the TGIF1 (-) group at 2 weeks and 4 weeks (Fig. 4B), which indicated increasing new bone and fibrocartilage formation in the TGIF1 (-) group than the other groups at 4 weeks. Conversely, the TGIF1 overexpressing group had dramatic fibrovascular scar tissue formation at the interface site. These data indicated that the overexpression of TGIF1 in TDSCs modulated the upregulation of all the tendon markers, including Scx, Tnmd and Col I, and the upregulation of the fibrovascular scar tissue formation. The pro-inflammatory reactions induced by the overexpression of TGIF1 may also influence the formation of massive scar tissue, which can be further investigated.

Samples from TGIF1 siRNA transfected and TDSCs treated cells express higher levels of chondrogenic proteins

At 2 weeks, the expression level of chondrogenic markers and tendon markers in the protein lysates from all samples were evaluated by Western blotting. The protein levels of TGIF1, Smad2 and pSmad2 of four groups were detected by Western blotting (Fig. 5A). In the TGIF1 silencing group, the level of TGIF1 was largely decreased compared with the control groups, while the level of pSmad2 was significantly increased. The chondrogenic related genes and the fibrogenesis related genes were also detected (Fig. 5B). In the TGIF1 silencing group, Western blot showed significant differences in the protein levels of sox9, aggrecan and collagen II compared with the control groups and the TGIF1 overexpressing group. Furthermore, the protein levels of fibrogenesis markers (Scx, Tnmd and Col I) were largely reduced in the TGIF1 silencing group. The opposite results were obseved in the TGIF1 overexpressing group.

\section{KARGER}




\section{Cellular Physiology Cell Physiol Biochem 2015;37:2101-2114 \begin{tabular}{l|l} 
and Biochemistry Published online: November 25, 2015 & $\begin{array}{l}\text { C 2015 S. Karger AG, Basel } \\
\text { www.karger.com/cpb }\end{array}$ \\
\hline
\end{tabular} \\ Chen et al.: TDSCs Silencing TGIF1 Promote Tendon-to-Bone Healing}

At 4 weeks, the protein levels of TGIF1, Smad2 and pSmad2 were similar to the results at 2 weeks. The expression of sox9, aggrecan and collagen II were significantly elevated compared with the levels at 2 weeks in the TGIF1 silencing group. The contrary findings were found in the TGIF1 overexpressing group.

\section{Discussion}

Injuries at the bone tendon interface are common and can be classified as acute ruptures or chronic degenerations. A study [26] reported that $97 \%$ of spontaneously ruptured tendons showed histopathological changes, indicating chronic degeneration. Likewise, acutely ruptured tendons are significantly more degenerative than the tendinopathic tendons [4].

The long-term healing of the bone-tendon interface in a sheep model following a surgical reattachment of the patellar tendon to the patella was studied [27]. Light microscopy observation observation revealed the tendon merging seamlessly with the bone tissue. However, microscopic evaluation showed that the residues have hyper-cellularity, extracellular matrix disorganization, and no fibrocartilage layer. Therefore, general surgical approaches are not able to recapitulate the native fibrocartilaginous enthesis, which causes reduced mechanical functions and an increased risk of re-injury. Common tendon injuries are similar to tendon insertion injuries that heal with the replacement of the fibrovascular scar tissue to fibrocartilage, which causes chronic pain and stress induced un-comfortableness. To smoothen the healing process, regain full pledged function, or regain native structure has always been a clinical target for researchers. Tendon injuries caused by different kinds of modalities has similar outputs and healing procedures. However, the major cause is the degeneration or breaking erosion. Majority of the bone-tendon interface injuries involve fibrocartilaginous entheses, with which surgical repair failed to restore the natural structure [28].

To seek a solution for these tendon disorders, several studies explored the available treatment modalities to compare and select the best for patients with tendon injuries. Among the conservative treatments, there are NSAIDs, relative rest or immobilization and corticosteroid injections. Recent reports showed NSAIDs drugs has mild outcomes [3] and may inhibit the healing process [29]. Corticosteroid injections are administrated to treat pain and reduce inflammation. However, several tendon ruptures are reported after injection [27]. Other treatments included stimulation of the regeneration of tendon and other soft tissues [30-32]. Eccentric exercise is a type of exercise, which continues for 12 weeks to improve the function. However, the success rate was low $[33,34]$. Surgery is considered as the last option for patients though research showed that the results are variable [5]. Treatment modalities in the literatures mostly focused on the management of pain and inflammation. This current study aimed to strengthen the effort of exploration of regenerative tool for tendon healing.

TGF- $\beta$ plays an important role in the physiological healing process of tendon insertion injuries [35]. TGF $\beta$ induced Smad-mediated signaling pathway is also influenced by the inhibitory Smads (I-Smads, Smad 6 and 7) and Smad co-repressor. The transcriptional Smad co-repressor, TGIF1, is a member of the three-amino-acid loop extension (TALE) super family of HD (histone deacetylasedependent) proteins. TGIF1 is also involved in the proinflammatory responses whereas the silence of TGIF1 limits the inflammatory responses and leads to quick healing process [15].

Tendon progenitors in both the axial and appendicular musculoskeletal system upregulate Scx in early development and maintain its expression following by the maturation into tenocytes. Scx is considered to be the most selective markers of tendon and ligament differentiation. Scx heterodimerizes with bHLH protein E47 to selectively bind to cisacting elements that control collagen type 1 expression [36]. Scx plays an important role in tenocyte-mediated fibrillogenesis [37], Asou et al. [38] found that Scx expression was closely associated with Sox9. Soeda et al. [39] demonstrated that at least some of the cells in the tendons and ligaments originate from Sox9 expressing mesenchymasl cells in the cartilage 
primordial, suggesting their contribution to the formation of tendons. Recently, it was shown that a Scx/Sox9 progenitor pool contributes to the establishment of the interface between cartilage and tendon in the development of murine embryo [40].

The potential mechanisms to explain the failed healing process is yet unknown. Differentiation of tendon and cartilage is regulated in a balance of the expression of chondrogenic versus tenogenic genes in the connective tissue cell precursors $[41,42]$. TGF $\beta$ functions as a profibrogenic or a prochondrogenic factor. Pryce et al. [43] reported that TGF $\beta$ from the muscles and cartilages are essential for tendon formation at E12.5, and that TGF $\beta$ s from the tendon progenitors also contribute to the maintenance of tendon markers in these cells. In this study, the first indication of tendon loss was seen in mutant embryos at E12.5. Scx expression in the somites of Tgfb2 ${ }^{-/-}$embryos was markedly reduced. Mesenchymal stem cells were shown to undergo cellular condensation and chondrogenesis in the presence of regulatory factors such as TGF- $\beta$ in vitro [44].

The initial injury causes inferior mechanical damage and an increased risk of re-injuries. Recent in vivo studies provided evidence of improvement in healing when surgical repair of the bone-tendon interface is augmented with cells capable of undergoing chondrogenesis. Cellular therapy in bone-tendon healing can promote fibrocartilage formation and associated improvements in mechanical properties [25].

Lorda-Diez et al. [8] showed a different effect of TGF- $\beta$ in the signaling on chodrogenesis and fibrogenesis when comparing an in vitro to in vivo experimental model. Namely, TGF- $\beta$ supplementation of a high-density micromass culture suppressed chondrogeneic markers Sox9 and Aggrecan, while upregulaton of fibrogeneic markers Scx and Tenomodulin. Conversely, TGF- $\beta$ up regulated the Sox 9 in vivo, thereby inducing ectopic chondogenesis. Additionally, limb mesodermal cells cultured in a TGF- $\beta$ supplemented medium showed a downregulation of Sox9 and Aggrecan expression when transfected with TGIF.

In a previous study, TDSC exhibited higher clonogenicity, faster proliferation, and higher expression of tenomodulin, scleraxis, collagen 1 a 1 (Col1A1), decorin, alkaline phosphatase, Col2A1, and biglycan messenger RNA levels than BMSC [18]. There was higher calcium nodule formation and osteogenic marker expression in TDSC [45]. TDSC expressed higher Oct4 levels, which can positively regulate mesendodermal lineage differentiation, with clonogenicity and proliferative capacity. A greater tenogenic, osteogenic, chondrogenic, adipogenic markers and differentiation potentials than BMSC were observed. Chen et al. reported that PRP combined with TDSCs is potentially effective for the treatment of tendinopathy [46]. Therefore, TDSC might be a better cell source to study musculoskeletal tissue regeneration.

There are several limitations to this study. First, the histological analysis in our study was performed at two and four weeks. The long-term observation has been studied in the literature $[28,47]$, but the effect of early treatment for the injury might be a better guidance. Although a lack of the long-term effect limits this study, we follow up tendon healing after treatments up to 4 weeks. The promotion at early stage of tendon healing may allow earlier rehabilitation and better clinical outcome after injury. Second, this is a pilot study using small experimental animals, in which the evaluation tools are limited. A Partial tendon transection model was employed in our study, while other studies use a full-thickness rotator cuff tendon defect [28]. Further study is needed to compare the effect of the two models. Finally, many other growth factors and extracellular matrix proteins could be involved in this complex healing process. Our data should be considered in this context. A further study is in progress in order to observe the long-term effect and underlying molecular mechanisms on this basis.

The current study demonstrated that, chondrogenic markers (Sox9, Aggrecan and Collagen type II) were significantly upregulated in the TGIF1 gene-silencing group and were reduced significantly in the TGIF1 gene-overexpressing group. The expression of tendon markers (Scleraxis, Tenomodulin and Collagen type 1) was upregulated in TGIF1 overexpressing group. Similarly TGIF1 silencing accelerated the differentiation of TDSC into cartilage through interaction with TGF $\beta$-activated Smad2. TGIF1 silencing also suppressed the phosphorylation of Smad2, which is beneficial for the quick healing process. All the

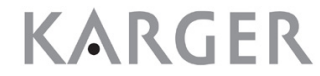




\section{Cellular Physiology Cell Physiol Biochem 2015;37:2101-2114 \begin{tabular}{ll|l} 
and Biochemistry & $\begin{array}{l}\text { DOI: 10.1159/000438568 } \\
\text { Published online: November 25, 2015 }\end{array}$ & $\begin{array}{l}\text { ( ) } 2015 \text { S. Karger AG, Basel } \\
\text { www.karger.com/cpb }\end{array}$ \\
\hline
\end{tabular} \\ Chen et al.: TDSCs Silencing TGIF1 Promote Tendon-to-Bone Healing}

findings demonstrated that the tendon-derived stem cells customized with the silenced TGIF1 gene improve the regeneration at the tendon-to-bone insertion site.

\section{Acknowledgments}

This work was supported by grants from Natural Science Foundation of China (No.81372005), Science Foundation of Zhejiang Province (LY13H060005), Public Technology Applied Research Projects of Zhejiang Province (2014C33254), General Foundation of Zhejiang Province (2013KYA201, 2012KYB213) and Shaoxing Science Project (No.2013B70081, 2014B70075).

\section{Disclosure Statement}

We declare that we have no conflict of interest.

\section{References}

1 Wong MW, Qin L, Tai JK, Lee SK, Leung KS, Chan KM: Engineered allogeneic chondrocyte pellet for reconstruction of fibrocartilage zone at bone-tendon junction--a preliminary histological observation. J Biomed Mater Res B Appl Biomater 2004;70:362-367.

2 Thomopoulos S, Williams GR, Soslowsky LJ: Tendon to bone healing: differences in biomechanical, structural, and compositional properties due to a range of activity levels. J Biomech Eng 2003;125:106113.

3 Rees JD, Maffulli N, Cook J: Management of tendinopathy. Am J Sports Med 2009;37:1855-1867.

4 Sharma P, and Maffulli N: Biology of tendon injury: healing, modeling and remodeling. J Musculoskelet Neuronal Interact 2006;6:181-190.

5 Rees JD, Wilson AM, Wolman RL: Current concepts in the management of tendon disorders. Rheumatology (Oxford) 2006;45:508-521.

6 Benjamin M, Kumai T, Milz S, Boszczyk BM, Boszczyk AA, Ralphs JR: The skeletal attachment of tendons-tendon "entheses". Comp Biochem Physiol A Mol Integr Physiol 2002;133:931-945.

7 Galatz L, Rothermich S, VanderPloeg K, Petersen B, Sandell L, Thomopoulos S: Development of the supraspinatus tendon-to-bone insertion: localized expression of extracellular matrix and growth factor genes. J Orthop Res 2007;25:1621-1628.

8 Lorda-Diez CI, Montero JA, Martinez-Cue C, Garcia-Porrero JA, Hurle JM: Transforming growth factors beta coordinate cartilage and tendon differentiation in the developing limb mesenchyme. J Biol Chem 2009;284:29988-29996.

9 Ylarinne JH, Qu C, Lammi MJ: Hypertonic conditions enhance cartilage formation in scaffold-free primary chondrocyte cultures. Cell Tissue Res 2014;358:541-550.

10 Wotton D, Lo RS, Lee S, Massague J: A Smad transcriptional corepressor. Cell 1999;97:29-39.

11 Yan L, Womack B, Wotton D, Guo Y, Shyr Y, Dave U, Li C, Hiebert S, Brandt S, Hamid R: Tgif1 regulates quiescence and self-renewal of hematopoietic stem cells. Mol Cell Biol 2013;33:4824-4833.

12 Chen F, Ogawa K, Nagarajan RP, Zhang M, Kuang C, Chen Y: Regulation of TG-interacting factor by transforming growth factor-beta. Biochem J 2003;371:257-263.

13 Hneino M, Francois A, Buard V, Tarlet G, Abderrahmani R, Blirando K, Hoodless PA, Benderitter M, Milliat F: The TGF-beta/Smad repressor TG-interacting factor 1 (TGIF1) plays a role in radiation-induced intestinal injury independently of a Smad signaling pathway. PLoS One 2012;7:e35672.

14 Cheng B, Ge H, Zhou J, Zhang Q: TSG-6 mediates the effect of tendon derived stem cells for rotator cuff healing. Eur Rev Med Pharmacol Sci 2014;18:247-251.

15 Li J, Chen L, Sun L, Chen H, Sun Y, Jiang C, Cheng B: Silencing of TGIF1 in bone mesenchymal stem cells applied to the post-operative rotator cuff improves both functional and histologic outcomes. J Mol Histol 2015;46:241-249. 


\section{Cellular Physiology Cell Physiol Biochem 2015;37:2101-2114

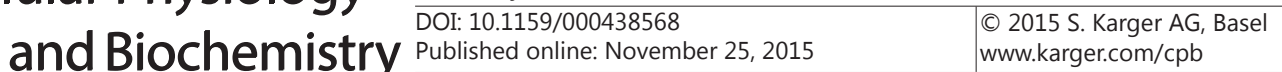 \\ Chen et al.: TDSCs Silencing TGIF1 Promote Tendon-to-Bone Healing}

16 Zhang Q, Zhou J, Ge H, Cheng B: Tgif1 and SnoN modified chondrocytes or stem cells for tendon-bone insertion regeneration. Med Hypotheses 2013;81:163-166.

17 Liu Y, Xie C, Zhang X, Huang D, Zhou X, Tan P, Qi L, Hu G, Tian Y, Qiu Y: Elevated expression of HMGB1 in squamous-cell carcinoma of the head and neck and its clinical significance. Eur J Cancer 2010;46:30073015.

18 Tan Q Lui PP, Rui YF, Wong YM: Comparison of potentials of stem cells isolated from tendon and bone marrow for musculoskeletal tissue engineering. Tissue Eng Part A 2012;18:840-851.

19 Rui YF, Lui PP, Li G, Fu SC, Lee YW, Chan KM: Isolation and characterization of multipotent rat tendonderived stem cells. Tissue Eng Part A 2010;16:1549-1558.

20 Abarrategi A, Perez-Tavarez R, Rodriguez-Milla MA, Cubillo I, Mulero F, Alfranca A, Lopez-Lacomba JL, Garcia-Castro J: In vivo ectopic implantation model to assess human mesenchymal progenitor cell potential. Stem Cell Rev 2013;9:833-846.

21 Wotton D, Lo RS, Swaby LA, Massague J: Multiple modes of repression by the Smad transcriptional corepressor TGIF. J Biol Chem 1999;274:37105-37110.

22 Kretzschmar M, Doody J, Timokhina I, Massague J: A mechanism of repression of TGFbeta/ Smad signaling by oncogenic Ras. Genes Dev 1999;13:804-816.

23 Pessah M, Prunier C, Marais J, Ferrand N, Mazars A, Lallemand F, Gauthier JM, Atfi A: c-Jun interacts with the corepressor TG-interacting factor (TGIF) to suppress Smad2 transcriptional activity. Proc Natl Acad Sci U S A 2001;98:6198-6203.

24 Prunier C, Ferrand N, Frottier B, Pessah M, Atfi A: Mechanism for mutational inactivation of the tumor suppressor Smad2. Mol Cell Biol 2001;21:3302-3313.

25 Gulotta LV, Kovacevic D, Montgomery S, Ehteshami JR, Packer JD, Rodeo SA: Stem cells genetically modified with the developmental gene MT1-MMP improve regeneration of the supraspinatus tendon-to-bone insertion site. Am J Sports Med 2010;38:1429-1437.

26 Ni M, Lui PP, Rui YF, Lee YW, Lee YW, Tan Q Wong YM, Kong SK, Lau PM, Li G, Chan KM: Tendon-derived stem cells (TDSCs) promote tendon repair in a rat patellar tendon window defect model. J Orthop Res 2012;30:613-619.

27 Newsham-West R, Nicholson H, Walton M, Milburn P: Long-term morphology of a healing bone-tendon interface: a histological observation in the sheep model. J Anat 2007;210:318-327.

28 Zhao S, Peng L, Xie G, Li D, Zhao J, Ning C: Effect of the Interposition of Calcium Phosphate Materials on Tendon-Bone Healing During Repair of Chronic Rotator Cuff Tear. Am J Sports Med 2014;42:1920-1929.

29 Kannus P, Jozsa L: Histopathological changes preceding spontaneous rupture of a tendon. A controlled study of 891 patients. J Bone Joint Surg Am 1991;73:1507-1525.

30 Ferry ST, Dahners LE, Afshari HM, Weinhold PS: The effects of common anti-inflammatory drugs on the healing rat patellar tendon. Am J Sports Med 2007;35:1326-1333.

31 Bulthaup S, Cipriani DJ, 3rd, Thomas JJ: An electromyography study of wrist extension orthoses and upperextremity function. Am J Occup Ther 1999;53:434-440.

32 Kleinman M, Gross AE: Achilles tendon rupture following steroid injection. Report of three cases. J Bone Joint Surg Am 1983;65:1345-1347.

33 Davidson CJ, Ganion LR, Gehlsen GM, Verhoestra B, Roepke JE, Sevier TL: Rat tendon morphologic and functional changes resulting from soft tissue mobilization. Med Sci Sports Exerc 1997;29:313-319.

34 Sevier TL, Wilson JK: Treating lateral epicondylitis. Sports Med 1999;28:375-380.

35 Kim HM, Galatz LM, Das R, Havlioglu N, Rothermich SY, Thomopoulos S: The role of transforming growth factor beta isoforms in tendon-to-bone healing. Connect Tissue Res 2011;52:87-98.

36 Ito Y, Toriuchi N, Yoshitaka T, Ueno-Kudoh H, Sato T, Yokoyama S, Nishida K, Akimoto T, Takahashi M, Miyaki S, Asahara H: The Mohawk homeobox gene is a critical regulator of tendon differentiation. Proc Natl Acad Sci U S A 2010;107:10538-10542.

37 Thomopoulos S, Genin GM, Galatz LM: The development and morphogenesis of the tendon-to-bone insertion - what development can teach us about healing. J Musculoskelet Neuronal Interact 2010;10:3545.

38 Thomopoulos S, Williams GR, Gimbel JA, Favata M, Soslowsky LJ: Variation of biomechanical, structural, and compositional properties along the tendon to bone insertion site. J Orthop Res 2003;21:413-419. 


\section{Cellular Physiology Cell Physiol Biochem 2015;37:2101-2114 and Biochemistry

39 Soeda T, Deng JM, de Crombrugghe B, Behringer RR, Nakamura T, Akiyama H: Sox9-expressing precursors are the cellular origin of the cruciate ligament of the knee joint and the limb tendons. Genesis 2010;48:635644.

40 Carlberg AL, Tuan RS, Hall DJ: Regulation of scleraxis function by interaction with the bHLH protein E47. Mol Cell Biol Res Commun 2000;3:82-86.

41 Lorda-Diez CI, Montero JA, Garcia-Porrero JA, Hurle JM: Divergent differentiation of skeletal progenitors into cartilage and tendon: lessons from the embryonic limb. ACS Chem Biol 2014;9:72-79.

42 Montero JA, Lorda-Diez CI, Hurle JM: Regenerative medicine and connective tissues: cartilage versus tendon. J Tissue Eng Regen Med 2012;6:337-347.

43 Pryce BA, Watson SS, Murchison ND, Staverosky JA, Dunker N, Schweitzer R: Recruitment and maintenance of tendon progenitors by TGFbeta signaling are essential for tendon formation. Development 2009;136:1351-1361.

44 Sekiya I, Vuoristo JT, Larson BL, Prockop DJ: In vitro cartilage formation by human adult stem cells from bone marrow stroma defines the sequence of cellular and molecular events during chondrogenesis. Proc Natl Acad Sci U S A 2002;99:4397-4402.

45 Liu X, Chen W, Zhou Y, Tang K, Zhang J: Mechanical Tension Promotes the Osteogenic Differentiation of Rat Tendon-derived Stem Cells Through the Wnt5a/Wnt5b/JNK Signaling Pathway. Cell Physiol Biochem 2015;36:517-530.

46 Chen L, Liu JP, Tang KL, Wang Q, Wang GD, Cai XH, Liu XM: Tendon derived stem cells promote platelet-rich plasma healing in collagenase-induced rat achilles tendinopathy. Cell Physiol Biochem 2014;34:2153-2168.

47 Galatz LM, Sandell LJ, Rothermich SY, Das R, Mastny A, Havlioglu N, Silva MJ, Thomopoulos S: Characteristics of the rat supraspinatus tendon during tendon-to-bone healing after acute injury. J Orthop Res 2006;24:541-550. 